\title{
Trypanosoma evansi Isolated from Capybara (Hidrochaeris hidrochaeris)
}

\begin{abstract}
Karina Muñoz, Amanda Chávez*/+
Estación Experimental de Iquitos, Centro de Investigación IVITA, Iquitos, Perú *Laboratorio de Parasitología, Facultad de Medicina Veterinaria, Universidad Nacional Mayor de San Marcos, Av. Circunvalación s/n, Cdr. 28, San Borja, Lima, Perú

A study was conducted to determine the morphological and biometric characteristics of Trypanosoma isolated from 50 capybaras animals, raised in captivity in the Peruvian Amazon. Trypanosoma was found in 14 blood samples using the microhaematocrit, wide drop, and Giemsa-stain methods and $\mathrm{T}$. evansi was identified through morphological details in all 14 positive samples (the subterminal kinetoplast, the developed undulating membrane, and a long free flagellum were used for the identification of the agent).
\end{abstract}

Key words: Trypanosoma evansi - morphometry - capybara - Peruvian Amazon

Trypanosoma evansi was first identified as a pathogenic agent for mammals by Griffith Evans (Soulsby 1982). This agent was disseminated throughout Centre and South America since its introduction from Spain, probably in the XVI century (Hoare 1965). T. evansi can be found in South America, both in domestic and wild animals including the capybara (Hidrochaeris hidrochaeris) (Mingoe 1910, Morales et al. 1976).

Biochemical characterization of the parasite has been conducted in Brazil in parasites accidentally found in blood smears from wild capybaras as well in those raised in captivity (Stevens 1989). However, morphological studies on Trypanosoma in wild animals have not been performed in the tropics of Perú and therefore, the objective of the present study was to determine the morphological and biometric characteristics of Trypanosoma isolated from animals raised in captivity in the Peruvian Amazon.

The study was conducted in 50 healthy capybaras. The animals were born in a common natural habitat and raised in captivity for at least one year at the breeding centre of the "Biodiversidad Amazónica" (BIOAM), located in Iquitos, Perú. Blood samples were collected in sterile test tubes containing EDTA and transported for analysis to the nearby parasitology laboratory of the Veterinary Tropical and High Altitude Research Insti-

\footnotetext{
${ }^{+}$Corresponding author. Fax: +51-1-435.3064. E-mail: a_chavez_g@hotmail.com

Received 7 June 2000

Accepted 22 June 2001
}

tute. Trypanosoma in blood samples was evaluated using the microhaematocrit, wide drop, and Giemsa-stain methods. Positive samples were sent to the Faculty of Veterinary Medicine, San Marcos University, in Lima and T. evansi was identified through morphological details in all 14 positive samples. In total, 100 parasites were identified according to the guidelines provided by Ramírez et al. (1997).

The subterminal kinetoplast, the developed undulating membrane, and a long free flagellum were used for the identification of the agent. The following measurements were considered: PN-length from posterior end to the middle of nucleous; NA-length from the nucleous to the anterior end; F-length of the free flagellum; L-total length including the free flagellum; PN/PA-nucleous index. The size (mean \pm s.d., in $\mu \mathrm{m}$ ) of the evaluated parasites is shown in the Table.

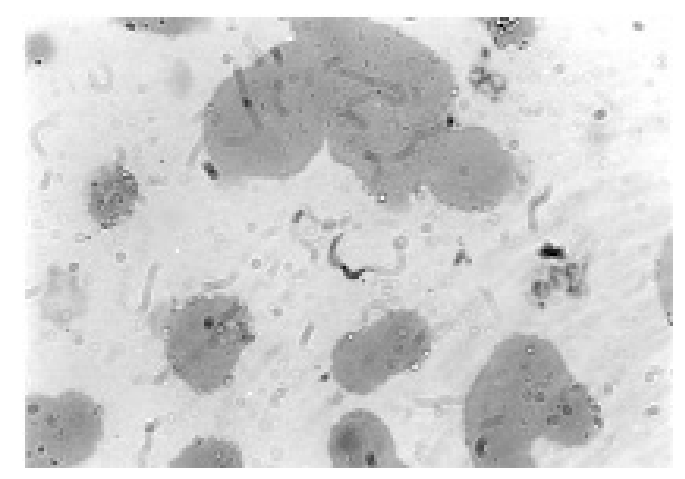

Photomicrograph of Trypanosoma evansi isolated from capybara. 


\section{TABLE}

Measurements of Trypanosoma evansi isolated in capybara (Hydrochaeris hydrochaeris) raised in captivity in the Peruvian Amazon

\begin{tabular}{lccccc}
\hline & PN & NA & F & L & PN/NA \\
\hline Mean $\pm \operatorname{sd}(\mu \mathrm{m})$ & $6.31 \pm 1.09$ & $4.46 \pm 1.04$ & $6.45 \pm 1.86$ & $17.14 \pm 2.69$ & $1.46 \pm 0.29$ \\
Range & $4.38-8.76$ & $2.92-7.30$ & $2.92-10.22$ & $10.22-23.36$ & $1.0-2.5$ \\
\hline
\end{tabular}

PN: from the posterior end to the middle of nucleous; NA: from the nucleous to the anterior end; F: free flagellum length; L: total length including the free flagellum; PN/PA: nucleous index; sd: standard deviation

The morphology of the Trypanosoma observed in the study corresponds to those reported by Gardiner and Musa (1992) and Soulsby (1982). However, some other characteristics reported by Losos (1980) such as parasites without kinetoplast or rounded shapes were not found.

\section{REFERENCES}

Gardiner P, Musa M 1992. Salivarian tripanosoma causing disease in livestock outside Sub Sahara, Africa. Parasitic Protozoa 2: 227-314.

Hoare C 1965. Vampire bats as vectors and host of equine and bovine trypanosomes. Acta Trop 22: 204-216.

Losos G 1980. Diseases caused by Trypanosoma evansi. A review. Vet Res Comm 4: 165-181.
Mingoe L 1910. Le role des caroinchos comme resevoir de virus dans la conservation de mal de cadeiras. Bull Soc Pathol Exot 3: 525-525.

Morales G, Wells E, Angel D 1976. The capybara (Hydrochaeris hidrochaeris) as reservoir host for Trypanosoma evansi. J Wild Dis 12: 572-574.

Ramírez L, Davila A, Victoriano A, Silva R, Trajamo V, Jansen A 1997. Measurement of Trypanosoma evansi isolated from the Pantanal. Mem Inst Oswaldo Cruz 92: 483-484.

Soulsby EJL 1982. Parasitología y Enfermedades Parasitarias en los Animales Domésticos, 7th ed., Interamericana, Mexico, p. 539-541.

Stevens J 1989. Isoensyme characterization of Trypanosoma evansi isolate from capybara and dog in Brazil. Acta Trop 46: 213-222. 